\title{
Features associated with myocardial ischemia in anomalous aortic origin of a coronary artery: A Congenital Heart Surgeons' Society study
}

Anusha Jegatheeswaran, MD, PhD, ${ }^{\mathrm{a}}$ Paul J. Devlin, MD, MSc, ${ }^{a}$ Brian W. McCrindle, MD, MPH, William G. Williams, MD, ${ }^{\mathrm{a}}$ Marshall L. Jacobs, MD, ${ }^{\mathrm{c}}$ Eugene H. Blackstone, MD, William M. DeCampli, MD, PhD, ${ }^{\mathrm{e}}$ Christopher A. Caldarone, MD, ${ }^{\mathrm{a}} \mathrm{J}$. William Gaynor, MD, ${ }^{\mathrm{f}}$ James K. Kirklin, MD, ${ }^{\mathrm{g}}$ Richard O. Lorber, MD, ${ }^{\mathrm{h}}$ Carlos M. Mery, MD, MPH, ${ }^{\mathrm{i}}$ James D. St. Louis, MD, Silvana Molossi, MD, PhD, ${ }^{\mathrm{k}}$ and Julie A. Brothers, $\mathrm{MD}^{\mathrm{l}}$

\section{ABSTRACT}

Objectives: We sought to determine anatomic features associated with evidence of myocardial ischemia and sudden cardiac events (arrest or death) for patients with anomalous aortic origin of a coronary artery.

Methods: We enrolled 560 patients, less than or equal to 30 years, at diagnosis from 40 institutions. Ischemia was defined as the presence of exertional syncope, a sudden cardiac event (arrest/death), or abnormal investigation results. Data on detailed anatomic features were abstracted from echocardiography, computed tomography, magnetic resonance imaging, operative, and/or surgeon-completed reports.

Results: There were 236 patients with negative ischemia test results, and 49 with evidence of ischemia (including 18 who presented with a sudden cardiac event); 275 asymptomatic patients who had not undergone provocative ischemia testing were excluded from primary analyses. Patients with ischemia (vs without), were more likely to have left anomalous coronary arteries $(28 / 49$ vs $46 / 236 ; P<.0001)$. Of patients with ischemia (vs without), those with anomalous left coronary arteries were more likely to have an intramural coronary artery course, or a high or slit-like coronary artery orifice. Of patients with ischemia (vs without), those with anomalous right coronary arteries were more likely to have a longer intramural course. Among patients with ischemia, the occurrence of sudden cardiac events was not shown to have any associated anatomic features.

Conclusions: Anatomic features including coronary artery involved, intramural course and length, and orifice anomalies were associated with evidence of myocardial ischemia for patients with anomalous aortic origin of a coronary artery. These features might importantly inform risk stratification and decisions regarding surgical management. (J Thorac Cardiovasc Surg 2019;158:822-34)

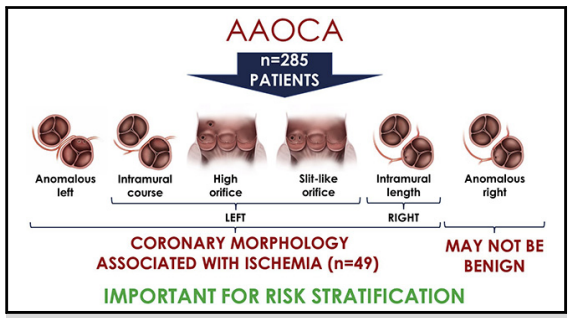

Primary findings related to myocardial ischemia in AAOCA.

\section{Central Message}

In anomalous aortic origin of a coronary artery, anomalous left coronary artery, intramural course, intramural length, and a high and/or slit-like orifice were associated with myocardial ischemia.

\section{Perspective}

Past studies of anomalous aortic origin of a coronary artery have been mainly autopsy and single institution series. We enrolled 560 patients, less than or equal to 30 years, with and without ischemia. Anomalous left coronary arteries, intramural course (presence and length), and high and/or slit-like orifice were associated with evidence of ischemia. These features might inform risk stratification and management.

See Commentary on page 835
From the ${ }^{\mathrm{a}}$ Division of Cardiac Surgery, Department of Surgery, and ${ }^{\mathrm{b}}$ Division of Cardiology, Department of Paediatrics, University of Toronto, Hospital for Sick Children, Toronto, Ontario, Canada; ${ }^{c}$ Division of Cardiac Surgery, Department of Surgery, Johns Hopkins University, Baltimore, $\mathrm{Md}$; ${ }^{\mathrm{d}}$ Department of Clinical Investigations, Heart and Vascular Institute, Cleveland Clinic Foundation, Cleveland, Ohio; ${ }^{e}$ Division of Cardiac Surgery, Department of Surgery, University of Central Florida, College of Medicine, Arnold Palmer Hospital for Children, Orlando, Fla; ${ }^{\mathrm{f}}$ Division of Cardiothoracic Surgery, Department of Surgery, Children's Hospital of Philadelphia, Philadelphia, Pa; ${ }^{\mathrm{g}}$ Division of Cardiothoracic Surgery, Department of Surgery, University of Alabama, School of Medicine, Birmingham, Ala; ${ }^{\mathrm{h}}$ Division of Cardiology, Department of Pediatrics, The Children's Hospital of San Antonio, Baylor College of Medicine, San Antonio, Tex; ${ }^{i}$ Division of Congenital Heart Surgery, Department of Surgery, and ${ }^{\mathrm{k}}$ Division of Cardiology, Department of Pediatrics, Texas Children's Hospital, Baylor College of Medicine, Houston, Tex; ${ }^{\mathrm{j}}$ Division of Cardiovascular Surgery, Department of Surgery, Children's Mercy Hospital and Clinics, Kansas City, Mo; and ${ }^{1}$ Division of Cardiology, Department of Pediatrics, The Children's Hospital of Philadelphia and Perelman School of Medicine at the University of Pennsylvania, Philadelphia, Pa.
Funding for this study provided to the Congenital Heart Surgeons' Society from Children's Mercy Hospitals and Clinics, The Michael H. Ludwig Memorial Foundation, Richard S. Wayne Endowed Chair of Pediatric Cardiology, Baylor College of Medicine/Children's Hospital of San Antonio.

Read at the 98th Annual Meeting of The American Association for Thoracic Surgery, San Diego, California, April 28-May 1, 2018.

Received for publication April 30, 2018; revisions received Feb 5, 2019; accepted for publication Feb 17, 2019; available ahead of print June 22, 2019.

Address for reprints: Anusha Jegatheeswaran, MD, PhD, Congenital Heart Surgeons Society, Room 4433, Black Wing Hospital for Sick Children, 555 University Ave, Toronto, Ontario M5G 1X8, Canada (E-mail: anusha.jegatheeswaran@utoronto. ca).

$0022-5223 / \$ 36.00$

Copyright (C) 2019 Published by Elsevier Inc. on behalf of The American Association for Thoracic Surgery

https://doi.org/10.1016/j.jtcvs.2019.02.122 


\section{Abbreviations and Acronyms \\ AAOCA = anomalous aortic origin of a coronary artery \\ $\mathrm{AAOLCA}=$ anomalous aortic origin of a left coronary artery \\ AAORCA $=$ anomalous aortic origin of a right coronary artery \\ CHSS = Congenital Heart Surgeons' Society \\ SCA = sudden cardiac arrest \\ SCD $\quad=$ sudden cardiac death}

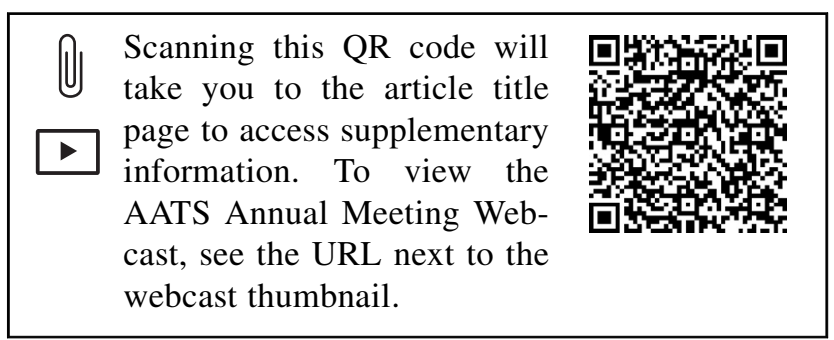

Anomalous aortic origin of a coronary artery (AAOCA) from the opposite sinus of Valsalva or with a high origin, which might have an interarterial, intramural, or intraconal course, is a rare congenital cardiac anomaly. It can be associated with myocardial ischemia (henceforth called ischemia) or sudden cardiac events (sudden cardiac arrest [SCA] or sudden cardiac death $[\mathrm{SCD}]){ }^{1}$ Although most patients with AAOCA are diagnosed incidentally, others are diagnosed on the basis of their presenting symptoms. ${ }^{2,3}$ The prevalence of AAOCA is estimated to be between $0.01 \%$ and $2 \%$ of the population. ${ }^{4}$ However, there are an unknown number of individuals who have not been diagnosed because they are asymptomatic, and potentially have not experienced conditions sufficient to precipitate a sudden cardiac event. In addition, there are numerous anatomical variations on the basis of the individual components of a patient's morphology (coronary artery involved, its location, course, and ostial features). As such, it remains unknown which anatomic features or combinations of features can put a patient at risk for ischemia and/or sudden cardiac events.

Although multiple anatomic and physiologic theories have been proposed, the exact causes of ischemia and sudden cardiac events are likely multifactorial and require nuanced interpretation. ${ }^{5-12}$ As such, risk stratification has proven difficult and surgical indications remain unclear. This is especially true in asymptomatic patients for whom one must determine if the risk of a sudden cardiac event is greater than the risk of an operation. ${ }^{4,13}$ Currently, the consensus guidelines only recommend an operation for those with ischemia or an interarterial left AAOCA
(AAOLCA). ${ }^{14}$ However, institutional and surgeon practices are highly varied.

In 2009, the Congenital Heart Surgeons' Society (CHSS) established this registry to clarify the natural and unnatural (surgically altered) history of AAOCA, including long-term outcomes, with the hope of informing risk stratification and management guidelines. The primary aims of the present study were to: (1) identify and compare the baseline characteristics of the entire cohort and the groups of interest (those with evidence of ischemia, with negative ischemia test results, with sudden cardiac events, and without sudden cardiac events), (2) characterize the best evidence of ischemia (most definitive) at presentation for patients with ischemia and sudden cardiac events, and (3) describe the anatomical features associated with evidence of ischemia and sudden cardiac events at presentation.

\section{METHODS \\ Patients}

Patients were enrolled retrospectively (January 1, 1998 to January 20, 2009) and prospectively (January 21, 2009 to December 31, 2016) from 40 CHSS institutions. Appendix E1 is a list of all enrolling institutions. Inclusion and exclusion criteria are listed in Appendix E2. We have previously reported the registry design and implementation, cohort descriptions, surgical management, accuracy of echocardiographic evaluation, and the effect of exercise restriction on body mass index. ${ }^{2,15-19}$

For this study, a patient was determined to have been tested for ischemia if he/she had undergone at least one provocative ischemia test. Provocative ischemia tests included cardiopulmonary exercise tests, stress echocardiograms, and nuclear perfusion scans. Patients were considered free of ischemia if they had undergone provocative testing and were found to be negative (henceforth called "patients without ischemia"). Patients were considered to have evidence of ischemia at diagnosis if they met the criteria described in Table 1 (henceforth called "patients with ischemia"). Of note, chest pain without the additional findings of positive biomarkers or electrocardiographic changes did not meet criteria. Patients with ischemia were further assessed for occurrence of a sudden cardiac event at diagnosis. Patients with a sudden cardiac event at diagnosis are henceforth called "sudden cardiac event patients," and patients without a sudden cardiac event are henceforth called "nonsudden cardiac event patients." Thus, we created 4 primary groups of patients in this study for comparison: the patients without ischemia versus the patients with ischemia, and within the group of patients with ischemia, the sudden cardiac event patients versus nonsudden cardiac event patients.

Those who were untested and asymptomatic could not be accurately classified (henceforth called "unclassified patients"). They were not included with the patients without ischemia, because we believed that these patients likely included some patients with ischemia, who had not been discovered A comparison of patients without ischemia versus unclassified patients was made to assess whether we appropriately excluded these patients.

Imaging and provocative testing were performed at the discretion of individual centers. These were not driven by registry-related protocols.

\section{Data Collection and Aggregation of Anatomical Features}

A description of data collection, and aggregation of anatomical features for each patient from multiple sources (echocardiogram, computed tomography, magnetic resonance imaging, surgical atomization) is provided in Appendix E2. The atomization form used for collection of detailed morphologic data (used once for each study) is provided in the Online Data Supplement. 


\section{Consent}

Institutional review board approval was obtained for the CHSS (institutional review board approval number, initial study approval date, and expiration date: 1000014078, March 12, 2010, March 13, 2018), and at each participating site. Informed consent/assent was acquired from all patients or parents (when indicated) before enrollment. All institutional and patient participation was voluntary.

\section{Statistical Analysis}

Descriptive statistics were performed for the following groups: entire cohort, unclassified patients, patients without ischemia, patients with ischemia, sudden cardiac event patients, nonsudden cardiac event patients. Best evidence of ischemia and mode of presentation for patients with ischemia was determined. For the primary comparison groups (patients without ischemia vs patients with ischemia, sudden cardiac event patients vs nonsudden cardiac event patients), descriptive and comparative statistics were performed according to totals, AAOLCA and anomalous aortic origin of a right coronary artery (AAORCA) patients within each group. Finally, first and second surgical procedures were broken down into their individual components for patients with ischemia (eg, unroofing, reimplantation, etc). Standard statistics were performed using SAS 9.4 (SAS Institute, Cary, NC; Appendix E2).

\section{RESULTS}

A total of 560 patients were enrolled (131 retrospective, 429 prospective). This included 275/560 (49\%) unclassified patients, $236 / 560(42 \%)$ patients without ischemia, and $49 / 560(9 \%)$ patients with ischemia. When we further reviewed the patients with ischemia for occurrence of sudden cardiac events, there were $31 / 49$ (63\%) nonsudden cardiac event patients, and 18/49 (37\%) sudden cardiac event patients. Figure $1, A$, depicts a flow diagram of patients in the cohort and the groups being compared. See Figure $1, B$, for a flow diagram of the entire cohort according to preoperative provocative testing, ischemia according to criteria at diagnosis, ischemia status, surgery, and coronary anatomy. A comparison of patients without ischemia and unclassified patients is shown in Table E1.

\section{Baseline Characteristics and Ischemia Status}

Baseline characteristics for the entire cohort and comparison groups are presented in Table 2. Several additional findings regarding the entire cohort and comparison groups are as follows. The proportion of African American patients with ischemia was significantly higher than that of other races $(16 / 34[47 \%]$ vs $35 / 131$ [27\%]; $P=.02)$. Within the cohort with known ischemia status (236 patients without ischemia +49 patients with ischemia $=285$ patients) 3 findings were notable: (1) prevalence of ischemia was significantly lower among AAORCA patients compared with AAOLCA patients $(10 \%$ [20/204] vs $38 \%$ [28/74]; $P<.0001$ ), (2) surgical intervention was common among all anomalies (55\% [228/413] AAORCA, 67\% [84/125] AAOLCA, and 63\% [5/8] with both), and (3) of the $13 / 560(2 \%)$ deceased patients in the cohort, mortality occurred with approximately equal frequency among AAOLCA (7 [54\%]) and AAORCA (6 [46\%]) patients.

\section{Best Evidence of Ischemia at Presentation and Mode of Presentation for Patients With Ischemia and Sudden Cardiac Events}

Table 3, section A describes the 49/285 (17\%) patients in the cohort who met the criteria for ischemia, noting their coronary artery anatomy and best evidence of

\section{TABLE 1. Criteria for ischemia}

A. Presentation with any of the following events:
a. Sudden cardiac death and/or
b. Sudden cardiac arrest and/or
c. Requirement for cardiopulmonary resuscitation and/or
d. Requirement for preoperative extracorporeal mechanical oxygenation

OR

B. Presenting symptom of:

a. Syncope during or after exercise not explained as by dehydration or as a vasovagal event OR

C. Preoperative or initial presentation with abnormal test:

a. Biomarkers (creatine kinase-muscle/brain or troponin I) above normal in the setting of congruent symptoms and/or

b. Ventricular tachycardia, infarction or ischemia on electrocardiogram in the same coronary artery territory as the anomalous coronary artery ${ }^{20}$ and/or

c. Abnormal cardiopulmonary exercise test with ST-segment changes in the same coronary artery territory as the anomalous coronary artery, exerciseinduced hypotension, and/or significant arrhythmia (eg, ventricular tachycardia) ${ }^{21}$

OR

D. Preoperative or initial presentation with abnormal imaging:

a. Abnormal perfusion scan with perfusion defect in the same coronary artery territory as the anomalous coronary artery and/or

b. Abnormal stress echocardiogram with wall motion abnormality in the same coronary artery territory as the anomalous coronary artery and/or

c. Abnormal magnetic resonance imaging with evidence of fibrosis or scar in the same coronary artery territory as the anomalous coronary artery and/or

d. Wall motion abnormalities in any modality with or without stress in the same coronary artery territory as the anomalous coronary artery 


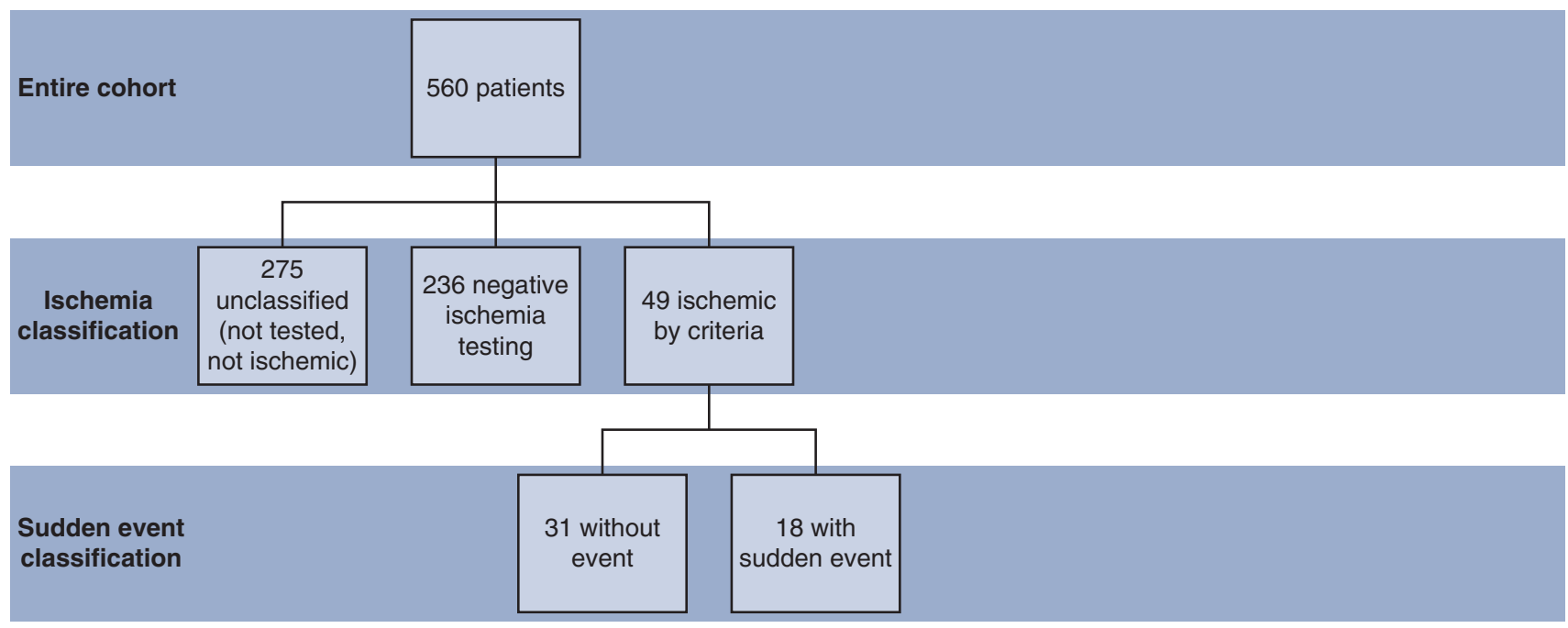

A

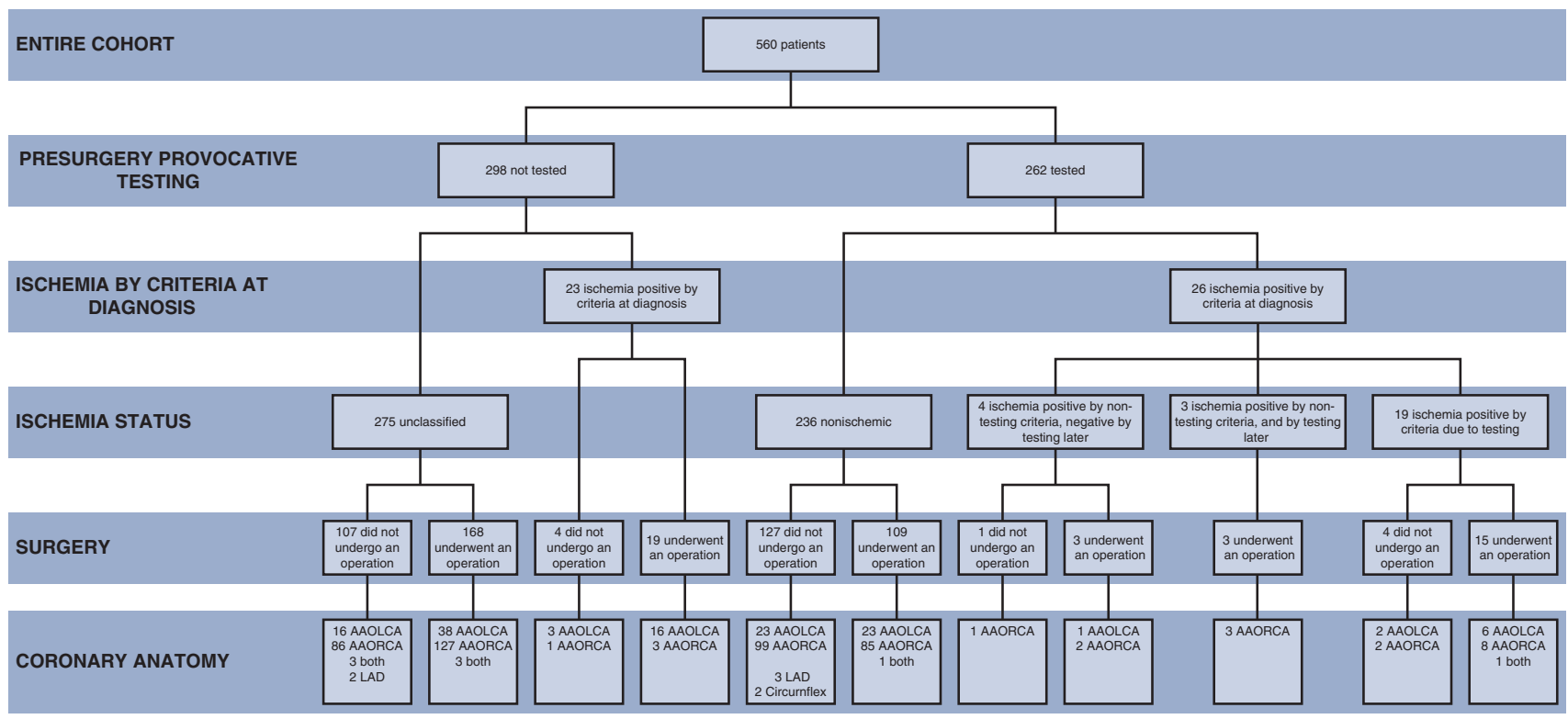

B

FIGURE 1. Flow diagram of patient classification in the cohort $(\mathrm{N}=560)$. A, Flow diagram showing comparison of patients. $\mathrm{B}$, Flow diagram of the entire cohort according to preoperative provocative testing, ischemia according to criteria at diagnosis, ischemia status, surgery, and coronary anatomy. $A A O L C A$, Anomalous aortic origin of a left coronary artery; AAORCA, anomalous aortic origin of a right coronary artery; $L A D$, left anterior descending.

ischemia at presentation. This includes the 18 patients who had a sudden cardiac event at presentation. Of the 49 patients, 12 presented because of some combination of symptoms/biomarkers/abnormal echocardiogram, 19 because of provocative testing, and 18 because of a sudden cardiac event (6 AAORCA, 12 AAOLCA). The distribution of sudden cardiac events among patients with AAORCA was $6 / 417(1 \%)$, and for AAOLCA was $12 / 128(9 \%)$.

Of patients with AAOLCA, the primary type of evidence was SCA $(11 / 28 ; 39 \%)$. SCD occurred in only 1 patient with AAOLCA. Of patients with AAORCA, the 2 primary types of evidence were abnormal nuclear perfusion stress test $(30 \%)$, and SCA $(30 \%)$. Of note, 1 patient with AAORCA and 3 with AAOLCA required mechanical circulatory support at the time of presentation.

Nearly all events in sudden cardiac event patients occurred with exertion $(16 / 18 ; 89 \%)$. Of the 2 cases without exertion, 1 had AAORCA and 1 had both.

The most common mode of presentation for ischemic patients in our cohort (either AAOLCA or AAORCA) was SCA (Table 3, section B). Most of the remaining ischemic patients presented with symptoms, and several were found incidentally during screening echocardiography. The 
TABLE 2. Baseline characteristics of entire cohort and patient groups

\begin{tabular}{|c|c|c|c|c|c|c|c|c|}
\hline & $\begin{array}{c}\text { All patients } \\
(\mathbf{N}=\mathbf{5 6 0})\end{array}$ & $\begin{array}{c}\text { Patients } \\
\text { without } \\
\text { ischemia } \\
(\mathbf{n}=\mathbf{2 3 6})\end{array}$ & $\begin{array}{l}\text { Patients } \\
\text { with } \\
\text { ischemia } \\
(n=49)\end{array}$ & $\begin{array}{c}\text { Patients } \\
\text { without } \\
\text { vs patients } \\
\text { with } \\
\text { ischemia }\end{array}$ & $\begin{array}{c}\text { Nonsudden } \\
\text { cardiac } \\
\text { event } \\
\text { patients } \\
(\mathbf{n}=\mathbf{3 1})\end{array}$ & $\begin{array}{c}\text { Sudden } \\
\text { cardiac } \\
\text { event } \\
\text { patients } \\
(\mathrm{n}=18)\end{array}$ & $\begin{array}{c}\text { Nonsudden } \\
\text { cardiac } \\
\text { event vs } \\
\text { sudden } \\
\text { cardiac } \\
\text { event } \\
\text { patients }\end{array}$ & $\begin{array}{c}\text { Unclassified } \\
\text { patients } \\
(n=275)\end{array}$ \\
\hline & $\begin{array}{l}\text { Median (IQR) } \\
\text { or n }(\%)\end{array}$ & $\begin{array}{l}\text { Median (IQR) } \\
\text { or } n(\%)\end{array}$ & $\begin{array}{c}\text { Median (IQR) } \\
\text { or } n(\%)\end{array}$ & $P$ value & $\begin{array}{c}\text { Median (IQR) } \\
\text { or n }(\%)\end{array}$ & $\begin{array}{c}\text { Median (IQR) } \\
\text { or } n(\%)\end{array}$ & $P$ value & $\begin{array}{c}\text { Median (IQR) } \\
\text { or } \mathbf{n}(\%)\end{array}$ \\
\hline $\begin{array}{l}\text { Diagnosis } \\
\text { age, } y\end{array}$ & $11.6(6.0-14.6)$ & $12.7(8.3-15.1)$ & $13.5(11.5-15.9)$ & .05 & $13.4(9.4-16.1)$ & $13.8(12.8-14.9)$ & 6 & $9.0(2.5-14.0)$ \\
\hline Male sex & $371(66)$ & $166(70)$ & $35(71)$ & .9 & $23(74)$ & $12(67)$ & 6 & $170(62)$ \\
\hline Race & & & & .1 & & & .4 & \\
\hline Caucasian & $140(47)$ & $65(50)$ & $11(32)$ & & $6(30)$ & $5(36)$ & & $64(47)$ \\
\hline $\begin{array}{l}\text { African } \\
\text { American }\end{array}$ & $92(31)$ & $35(27)$ & $16(47)$ & & $9(45)$ & $7(50)$ & & $41(30)$ \\
\hline Asian & $12(4)$ & $8(6)$ & 0 & & 0 & 0 & & $4(3)$ \\
\hline $\begin{array}{l}\text { Native } \\
\text { American }\end{array}$ & $2(1)$ & $1(1)$ & 0 & & 0 & 0 & & $1(1)$ \\
\hline Hispanic & $43(14)$ & $16(12)$ & $4(12)$ & & $4(20)$ & 0 & & $23(17)$ \\
\hline Other & $12(4)$ & $6(5)$ & $3(9)$ & & $1(5)$ & $2(14)$ & & $3(2)$ \\
\hline Missing & $\begin{array}{r}259(46 \% \\
\text { of total })\end{array}$ & $\begin{array}{r}105(44 \% \\
\text { of total) }\end{array}$ & $\begin{array}{l}15(31 \% \\
\text { of total })\end{array}$ & & $\begin{array}{l}11(35 \% \\
\text { of total) }\end{array}$ & $\begin{array}{l}4(22 \% \\
\text { of total })\end{array}$ & & $\begin{array}{r}139(51 \% \\
\text { of total })\end{array}$ \\
\hline \multicolumn{3}{|c|}{ Anomalous coronary artery } & & $<.0001$ & & & .7 & \\
\hline AAOLCA & $128(23)$ & 46 (19) & $28(57)$ & & $16(52)$ & $12(67)$ & & $54(20)$ \\
\hline AAORCA & $417(74)$ & $184(78)$ & $20(41)$ & & $14(45)$ & $6(33)$ & & $213(77)$ \\
\hline LAD & $5(1)$ & $3(1)$ & 0 & & 0 & 0 & & $2(1)$ \\
\hline Circumflex & $2(0.4)$ & $2(1)$ & 0 & & 0 & 0 & & 0 \\
\hline Both* & $8(1)$ & $1(0.4)$ & $1(2)$ & & $1(3)$ & 0 & & $6(2)$ \\
\hline Dead & $13(2)$ & $2(1)$ & $5(10)$ & .002 & $1(3)$ & $4(22)$ & .05 & $6(2)$ \\
\hline Surgery & $317 / 553$ (57) & $109 / 236$ (46) & 40/45 (89) & $<.0001$ & $25 / 30(83)$ & 15/15 (100) & 1 & $168 / 272(62)$ \\
\hline
\end{tabular}

In the surgical row, patients who died and were not eligible for surgery were removed from the denominator. IQR, Interquartile range; $A A O L C A$, anomalous aortic origin of a left coronary artery; AAORCA, anomalous aortic origin of a right coronary artery; $L A D$, left anterior descending. *Both denotes patients with AAOLCA and AAORCA.

proportion of patients among those with ischemia who were symptomatic was 29/49 (60\%; 17 AAOLCA, 11 AAORCA, 1 both), with the remaining 20/49 (41\%; 11 AAOLCA, and 9 AAORCA) asymptomatic.

\section{Comparison of Patient Groups With Respect to Anatomical Features, Surgery, and Mortality}

Table 4 provides the complete comparison of patients with ischemia (Table 4, section A) versus patients without ischemia (Table 4, section B). It also provides a comparison of sudden cardiac event patients (Table 4, section C) versus nonsudden cardiac event patients (Table 4, section D).

Within the known ischemia status group who had AAOLCA or AAORCA, ischemia was more common among AAOLCA patients than among AAORCA patients (38\% [28/74] vs 10\% [20/204]; $P<.0001$; Table 4, sections $\mathrm{A}$ and $\mathrm{B})$. Conversely, there were more AAORCA patients among those without ischemia versus with ischemia (184/236 [78\%] vs 20/49 [41\%]; $P<.0001$; Table 4, sections $\mathrm{A}$ and $\mathrm{B})$.
Compared with patients without ischemia who had AAOLCA, patients with ischemia who had AAOLCA were more likely to have an intramural course, high orifice, or slit-like orifice. Similarly, compared with patients without ischemia who had AAORCA, patients with ischemia who had AAORCA had a longer intramural course (Table 4, section B vs section A). Among the patients with ischemia, 48/49 $(98 \%)$ patients had an interarterial course, and $43 / 49(88 \%)$ had an intramural course (Table 4 , section B). Of note, these proportions for patients without ischemia and nonsudden cardiac event patients were $93 \%$ and $97 \%$ interarterial, and $78 \%$ and $90 \%$ intramural, respectively. Of note, there were no patients with ischemia who had a prepulmonic course, and there were 2 AAOLCA patients with ischemia who had a retroaortic course.

There were no significant differences among sudden cardiac event patients versus nonsudden cardiac event patients, when the proportions of AAOLCA (12/18 [67\%] vs $16 / 31[52 \%] ; P=.3)$, and AAORCA $(6 / 18[33 \%]$ vs 
TABLE 3. Best evidence of ischemia at presentation and mode of presentation in 49 patients with ischemia

\begin{tabular}{|c|c|}
\hline $\begin{array}{l}\text { A. Best evidence of ischemia according to } \\
\text { anomalous coronary artery }\end{array}$ & Patients, n (\%) \\
\hline \multicolumn{2}{|l|}{ AAOLCA $(n=28)$} \\
\hline Symptoms & $4(14)$ \\
\hline $\begin{array}{l}\text { Abnormal electrocardiogram, elevated biomarkers, } \\
\text { symptoms }\end{array}$ & $3(11)$ \\
\hline Abnormal echocardiogram & $1(4)$ \\
\hline Abnormal exercise electrocardiogram & $3(11)$ \\
\hline Abnormal stress echocardiogram & $2(7)$ \\
\hline Abnormal nuclear perfusion stress test & $3(11)$ \\
\hline $\begin{array}{l}\text { Biomarkers, symptoms, preoperatively mechanical } \\
\text { circulatory support }\end{array}$ & $1(4)$ \\
\hline $\begin{array}{l}\text { Symptoms, then sudden cardiac arrest with } \\
\text { preoperative mechanical circulatory support }\end{array}$ & $1(4)$ \\
\hline $\begin{array}{l}\text { Sudden cardiac arrest (then preoperative mechanical } \\
\text { circulatory support in } 1 \text { patient) }\end{array}$ & $9(32)$ \\
\hline Sudden cardiac death & $1(4)$ \\
\hline \multicolumn{2}{|l|}{$\operatorname{AAORCA}(\mathbf{n}=20)$} \\
\hline Symptoms & $2(10)$ \\
\hline Elevated biomarkers, and symptoms & $1(5)$ \\
\hline $\begin{array}{l}\text { Abnormal echocardiogram, elevated biomarkers, } \\
\text { and symptoms }\end{array}$ & $1(5)$ \\
\hline Abnormal exercise electrocardiogram & $2(10)$ \\
\hline Abnormal stress echocardiogram & $2(10)$ \\
\hline Abnormal nuclear perfusion stress test & $6(30)$ \\
\hline $\begin{array}{l}\text { Sudden cardiac arrest (then preoperative mechanical } \\
\text { circulatory support in } 1 \text { patient) }\end{array}$ & $6(30)$ \\
\hline \multicolumn{2}{|l|}{ Both (AAOLCA and AAORCA; $n=1)$} \\
\hline Abnormal nuclear perfusion stress test & $1(100)$ \\
\hline \multicolumn{2}{|l|}{$\begin{array}{l}\text { B. Mode of presentation according to anomalous } \\
\text { coronary artery }\end{array}$} \\
\hline \multicolumn{2}{|l|}{$\operatorname{AAOLCA}(n=28)$} \\
\hline Screening echocardiogram for hypertension & $1(4)$ \\
\hline Exercise test for asthma with ST depressions & $1(4)$ \\
\hline Palpitations & $1(4)$ \\
\hline Shortness of breath and palpitations & $1(4)$ \\
\hline Chest pain with activity & $2(7)$ \\
\hline Syncope with activity & $3(11)$ \\
\hline Syncope with activity and shortness of breath & $1(4)$ \\
\hline Syncope with activity and chest pain & $8(29)$ \\
\hline $\begin{array}{l}\text { Syncope with activity and shortness of breath, and } \\
\text { chest pain }\end{array}$ & $1(4)$ \\
\hline Sudden cardiac arrest & $9(32)$ \\
\hline \multicolumn{2}{|l|}{$\operatorname{AAORCA}(\mathbf{n}=\mathbf{2 0})$} \\
\hline $\begin{array}{l}\text { Screening echocardiogram for either: hypertension, } \\
\text { murmur, family history of cardiomyopathy, WPW }\end{array}$ & $4(20)$ \\
\hline Nausea, vomiting and hypotension with exercise & $1(5)$ \\
\hline Chest pain & $1(5)$ \\
\hline Chest pain and shortness of breath & $2(10)$ \\
\hline Chest pain with exercise & $1(5)$ \\
\hline Chest pain at rest & $1(5)$ \\
\hline
\end{tabular}

TABLE 3. Continued

B. Mode of presentation according to anomalous

coronary artery

\begin{tabular}{ll}
\hline Syncope with activity & $1(5)$ \\
Syncope with activity and palpitations & $1(5)$ \\
Syncope with activity and chest pain & $1(5)$ \\
$\begin{array}{l}\text { Syncope with activity, shortness of breath, } \\
\text { palpitations, and chest pain }\end{array}$ & $2(10)$ \\
\hline Sudden cardiac arrest & $5(25)$ \\
Both (AAOLCA and AAORCA; $\mathbf{n}=\mathbf{1})$ & $1(100)$ \\
$\quad$ Syncope with activity
\end{tabular}

Lightest shading indicates symptoms/biomarkers/abnormal echocardiogram, medium shading indicates abnormal provocative ischemia testing, and darkest shading indicates sudden cardiac events. AAOLCA, Anomalous aortic origin of a left coronary artery; AAORCA, anomalous aortic origin of a right coronary artery; WPW, WolffParkinson-White syndrome.

$14 / 31[45 \%] ; P=.4)$ within each group were compared (Table 4 , section $\mathrm{D}$ vs section $\mathrm{C}$ ). There was also no difference in specific anatomic features when AAOLCA and AAORCA patients within the sudden cardiac event patients versus nonsudden cardiac event patients were compared (Table 4, section D vs section C).

There were more patients with ischemia who had AAOLCA versus patients without ischemia who had AAOLCA, who underwent operation (23/25 [92\%] vs 23/46 [50\%]; $P=.0004)$. The same pattern was identified in patients with AAORCA (16/19 [84\%] vs 85/184 [46\%]; $P=.002)$. A mortality difference was not found when patients with ischemia who had AAOLCA versus patients without ischemia who had AAOLCA were compared (4/26 [14\%] vs $1 / 46[2 \%] ; P=.06)$. This was also the case for AAORCA patients $(1 / 20[5 \%]$ vs $1 / 184[1 \%] ; P=.2)$. See Table 4, section B versus Table 4, section A for the comparisons in this paragraph. There was a significantly greater proportion of sudden cardiac event patients who died (3 AAOLCA, 1 AAORCA) compared with nonsudden cardiac event patients who died (1 AAOLCA; 4/18 [22\%] vs $1 / 31$ $[3 \%$ ]; $P=.05$; Table 4 , section D vs Table 4 , section C).

Within the ischemic patients, there were 4 AAOLCA and 1 AAORCA patient who died. The 4 patients with AAOLCA died from either presumed or confirmed acute myocardial infarction. The patient with AAORCA died from heart failure secondary to a myocardial infarction. The diagnosis was made incidentally on autopsy.

\section{Coronary Anatomy, Provocative Testing, and Evidence of Ischemia in Surgical Patients}

Of the 317 surgical patients, $228(228 / 317 ; 72 \%)$ had AAORCA, $84(84 / 317 ; 26 \%)$ had AAOLCA, and $5(5 / 317 ; 2 \%)$ patients had both. Previous preoperative provocative testing was performed in 130/317 (41\%) patients. None of the patients in the cohort with isolated anomalous 
TABLE 4. Comparison of patient groups: patients without ischemia versus patients with ischemia, and nonsudden cardiac event patients versus sudden cardiac event patients

A. Patients without ischemia $(n=236)$

\begin{tabular}{|c|c|c|c|c|c|c|c|c|c|c|}
\hline \multirow{2}{*}{$\begin{array}{c}\text { Anomalous } \\
\text { coronary } \\
\text { artery }\end{array}$} & \multirow{2}{*}{$\begin{array}{c}\text { Total } \\
\mathbf{N}(\%)\end{array}$} & \multirow{2}{*}{$\begin{array}{l}\text { Dead } \\
\text { n }(\%)\end{array}$} & \multirow{2}{*}{$\begin{array}{c}\text { Surgery } \\
\text { n }(\%)\end{array}$} & \multirow{2}{*}{$\begin{array}{c}\text { Interarterial } \\
\mathbf{n}(\%)\end{array}$} & \multirow{2}{*}{\multicolumn{2}{|c|}{$\begin{array}{c}\text { Intramural } \\
\mathbf{n}(\%)\end{array}$}} & \multicolumn{2}{|c|}{ Intramural length, mm } & \multirow{2}{*}{$\begin{array}{c}\text { High orifice } \\
\text { n }(\%)\end{array}$} & \multirow{2}{*}{$\begin{array}{c}\text { Slit-like orifice } \\
\text { n }(\%)\end{array}$} \\
\hline & & & & & & & Median (IQR) & $\mathbf{M}, \mathbf{n}$ & & \\
\hline AAOLCA & $46 / 236(19)$ & $1 / 46(2)$ & $23 / 46(50)$ & $34 / 41(83)$ & & $/ 35(51)$ & $7.5(4.5-10)$ & 5 & $2 / 32(6)$ & $10 / 28(36)$ \\
\hline AAORCA & $184 / 236(78)$ & $1 / 184(1)$ & $85 / 184(46) \quad 1$ & 158/161 (98) & $114 /$ & $131(87)$ & $6(4.8-9)$ & 38 & $44 / 105(42)$ & $62 / 81(77)$ \\
\hline LAD & $3 / 236(1)$ & 0 & 0 & 0 & & 0 & 0 & 0 & 0 & 0 \\
\hline Circumflex & $2 / 236(1)$ & 0 & 0 & $1 / 2(50)$ & & 0 & 0 & 0 & 0 & 0 \\
\hline Both & $1 / 236(0.4)$ & 0 & (1/1) 100 & 0 & & $1 / 1(100)$ & 1.5 & 0 & $1 / 1(100)$ & $1 / 1(100)$ \\
\hline Total & $236 / 236(100)$ & $2 / 236(1)$ & $109 / 236(46) \quad 1$ & 193/208 (93) & $133 /$ & $170(78)$ & $6(4.5-9)$ & 43 & $47 / 140(34)$ & 73/111 (66) \\
\hline \multicolumn{11}{|c|}{ B. Patients with ischemia $(n=49)$} \\
\hline AAOLCA & $28 / 49(57)$ & $4 / 28(14)$ & $23 / 25(92)$ & $27 / 28(9$ & & $24 / 28(86)$ & $7(3-10)$ & 10 & $6 / 20(30)$ & $13 / 18(72)$ \\
\hline AAORCA & $20 / 49(41)$ & $1 / 20(5)$ & $16 / 19(884)$ & $20 / 20(1$ & & $18 / 20(90)$ & $8.5(7-10)$ & 4 & $9 / 18(50)$ & $12 / 14(86)$ \\
\hline Both & $1 / 49(2)$ & 0 & $1 / 1(100)$ & $1 / 1(1$ & & $1 / 1(100)$ & 4 & 0 & $1 / 1(100)$ & $1 / 1(100)$ \\
\hline Total & $49 / 49(100)$ & $5 / 49(10)$ & $40 / 45(89)$ & $48 / 49(9$ & & $43 / 49(88)$ & $8(5-10)$ & 14 & $16 / 39(41)$ & $26 / 33(79)$ \\
\hline \multicolumn{11}{|c|}{ A. vs B. $P$ values for patients without ischemia vs patients with ischemia } \\
\hline AAOLCA & $<.0001$ & .06 & .0004 & .13 & & .007 & .5 & & .04 & .02 \\
\hline AAORCA & $<.0001$ & .2 & .002 & 1 & & 1 & .04 & & .5 & .7 \\
\hline Total & - & .002 & $<.0001$ & .32 & & .14 & .3 & & .4 & .2 \\
\hline \multicolumn{11}{|c|}{ C. Nonsudden cardiac event patients $(n=31)$} \\
\hline AAOLCA & $16 / 31(52)$ & $1 / 16(6)$ & $13 / 15(87)$ & $15 / 16$ & & $14 / 16(88)$ & $7(4-10)$ & 4 & $5 / 13(38)$ & $7 / 12(58)$ \\
\hline AAORCA & $14 / 31(45)$ & 0 & $11 / 14(79)$ & $14 / 14$ & 100) & $13 / 14(93)$ & $9(8-10)$ & 4 & $6 / 12(50)$ & $7 / 9$ (78) \\
\hline Both & $1 / 31(3)$ & 0 & $1 / 1(100)$ & $1 / 1$ & 100) & $1 / 1(100)$ & 4 & 0 & $1 / 1(100)$ & $1 / 1(100)$ \\
\hline Total & $31 / 31(100)$ & $1 / 31$ (3) & $25 / 30(83)$ & $30 / 31$ & & $28 / 31(90)$ & $8(5.5-10)$ & 8 & $12 / 26(46)$ & $15 / 22(68)$ \\
\hline \multicolumn{11}{|c|}{ D. Sudden cardiac event patients $(n=18)$} \\
\hline AAOLCA & $12 / 18(67)$ & $3 / 12(25)$ & $10 / 10(100$ & $12 / 12$ & (100) & $10 / 12(83)$ & $5(2.8-8.5)$ & 6 & $1 / 7$ (14) & $6 / 6(100)$ \\
\hline AAORCA & $6 / 18$ & $1 / 6(17)$ & $5 / 5(100$ & $6 / 6$ & (100) & $5 / 6(83)$ & $8(7-10)$ & 0 & $3 / 6(50)$ & $5 / 5(100)$ \\
\hline Total & $18 / 18(100)$ & $4 / 18(22)$ & $15 / 15(100$ & $18 / 18$ & (100) & $15 / 18(83)$ & $7(3-10)$ & 6 & $4 / 13$ & $11 / 11(100)$ \\
\hline
\end{tabular}

C. vs D. $P$ values for nonsudden cardiac event patients vs sudden cardiac event patients

\begin{tabular}{lllllllll}
\hline AAOLCA & .4 & .3 & .5 & 1 & 1 & .5 & .4 & .1 \\
AAORCA & .4 & .3 & .5 & - & .5 & .6 & .4 \\
Total & - & .05 & .15 & 1 & .7 & .5 & .5 & .07 \\
\hline
\end{tabular}

Missing values not shown can be derived by comparing the denominator with the number of patients in the Total column. Both denotes patients with AAOLCA and AAORCA. High orifice denotes those at or above the sinotubular junction. In the surgical column, patients who died and were not eligible for surgery were removed from the denominator. $I Q R$, Interquartile range; $M$, missing; $A A O L C A$, anomalous aortic origin of a left coronary artery; $A A O R C A$, anomalous aortic origin of a right coronary artery; $L A D$, left anterior descending.

left anterior descending or isolated anomalous circumflex underwent an operation.

Although 236/262 (90\%) patients who underwent provocative testing were found to not have ischemia, nearly half $(109 / 236 ; 46 \%)$ still underwent an operation (23 AAOLCA, 85 AAORCA, 1 with both). Additionally, 187 patients underwent an operation without provocative testing (54 AAOLCA, 130 AAORCA, 3 with both). Finally, 132 patients did not have an operation, but had provocative testing, of which 5 were positive (2 AAOLCA, 3 AAORCA, all alive), and 127 were negative. The 2 AAOLCA patients are further described in the following section.

\section{Surgical Patients With Evidence of Ischemia}

Among patients with ischemia, 40 underwent an operation (23/45 [51\%] AAOLCA, 16/45 [36\%] AAORCA, and 1/45 [2\%] patient with both). Patients who died before an 
operation were removed from the denominator, leaving 45 patients. Primary surgical procedures included unroofing $(\mathrm{n}=35)$, patch ostioplasty $(\mathrm{n}=4)$, and reimplantation $(\mathrm{n}=3)$. For a demonstration of unroofing, please see Video 1. Reoperation occurred in $4 / 40(10 \%)$ patients to address ostial stenosis (3 AAOLCA [2 had postoperative symptoms and subsequent investigations, and 1 suffered a postoperative cardiac arrest]; and 1 AAORCA [reoperated on postoperative day 1 for arrhythmia]). See Table 5, section A for a listing of the primary procedures that patients with ischemia underwent, and Table 5, section B for a description of the reoperations that patients underwent. See Appendix E3 for a detailed description of the 9 patients with ischemia who did not undergo surgery (5 AAOLCA and 4 AAORCA).

\section{DISCUSSION}

Until recently, descriptions of AAOCA variants have been primarily limited to case reports, autopsy series, and single-institution series. ${ }^{1,9-11,22-28}$ These reports have suggested that high-risk anatomy primarily includes AAOLCA, especially in those with an interarterial course, and that interarterial AAOLCA is less common than interarterial AAORCA, although it carries a greater risk of sudden cardiac events. ${ }^{22-24,29,30}$ However, because of the rarity of diagnosed AAOCA and the low frequency of presentation with sudden cardiac events, evaluating the risk of ischemia and sudden cardiac events, and the features associated with each, in addition to surgical management, has proven difficult. Our cohort is unique in that it is a multi-institutional representation of children and young adults with and without ischemia in the general population, who might or might not be involved in sports and other physical activities. ${ }^{11,24-26}$

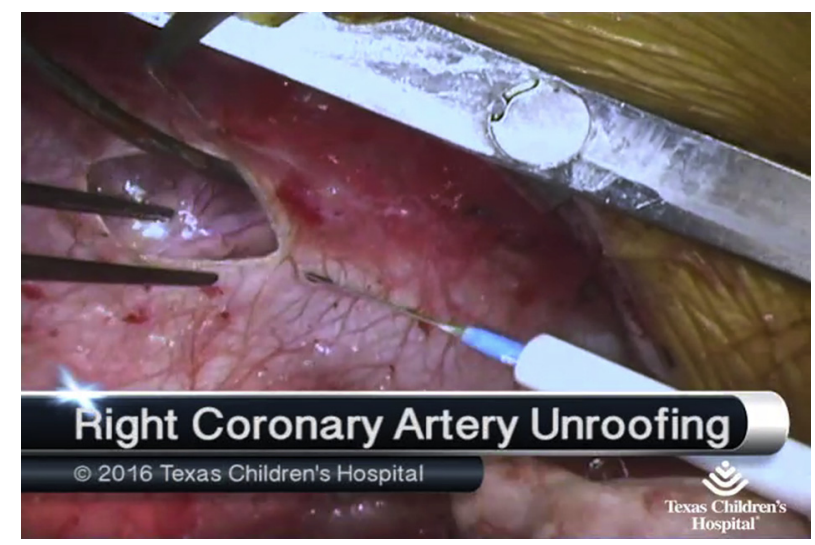

VIDEO 1. Unroofing of anomalous aortic origin of a right coronary artery in a patient with an intramural course. Video available at: https://www. jtcvs.org/article/S0022-5223(19)30701-9/fulltext.

\section{Race}

When examining demographic characteristics, race did seem to play a role because there was a higher proportion of African American patients within patients with ischemia versus patients without ischemia, compared with other races. Because this is, to our knowledge, the first time this association has been noted with AAOCA, further assessment is necessary in a population in which race is more completely captured. However, this might indicate a population that is at higher risk for ischemia, and who require more careful assessment and consideration for intervention.

\section{Age of Patients With Ischemia and Sudden Cardiac Events}

One possible explanation for why patients with ischemia were found to have a median age significantly older than those without ischemia is because older children are more likely to experience ischemia because of increasing intensity of exertion, sports practices, and competition compared with younger children. However, there was 1 sudden cardiac event that occurred as young as 6 years of age (interarterial, intramural AAOLCA). Although rare, it does suggest that an operation might be considered in select cases at a younger age in those with an interarterial and/or intramural AAOLCA course. This is younger than the previously suggested age of approximately 10 years, after which children are believed to be at higher risk of adequately exerting themselves and inducing an event. ${ }^{14}$ However, a patient's larger size when older might also make it safer to surgically address the coronary arteries, which will also be larger.

\section{Ischemia Testing}

Interestingly, in our cohort, there was a large number of patients who had not undergone provocative testing $(\mathrm{n}=275)$. This was the youngest group of patients with a median age of 9.0 years (interquartile range, 2.5-14.0). We believe that the lack of testing can be partially explained by the young age of this group, because likely some proportion were believed to be too young to undergo provocative testing. However, there were others, as evidenced by the upper end of the interquartile range, who were old enough to undergo some sort of provocative testing and did not. There were 127/210 (60\%) unclassified AAORCA patients who underwent surgical repair without any provocative testing, having had only anatomic imaging with echocardiography and/or axial imaging. This was not in keeping with what we would have expected because the current guidelines recommend provocative ischemia testing for AAORCA patients upon diagnosis to help in risk stratification. ${ }^{14}$ Provocative ischemia testing is likely a highly valuable source of information for baseline assessment, and for subsequent evaluation after an operation. 
TABLE 5. Primary procedures in surgical patients with ischemia

\begin{tabular}{|c|c|}
\hline Procedure 1 & Procedure 2 \\
\hline $\mathbf{N}=\mathbf{4 0}, \mathbf{M}=\mathbf{0}$ & $\mathrm{N}=\mathbf{4}, \mathrm{M}=\mathbf{0}$ \\
\hline Unroofing $=3(8 \%)$ AAOLCA with $\mathrm{CM}$ & Bypass graft $=1(25 \%)$ AAORCA \\
\hline Unroofing with tacking $=25(63 \%)(13$ AAOLCA $[9 \mathrm{CM}], 11$ AAORCA $[3 \mathrm{CM}], 1$ both $)$ & Patch ostioplasty $=2(50 \%)$ AAOLCA (1 CM) \\
\hline Unroofing, PA translocation $=1(3 \%)$ AAORCA & Ostioplasty $=1(25 \%)$ AAOLCA \\
\hline \multicolumn{2}{|l|}{ Unroofing with tacking, PA translocation $=2(5 \%)(1$ AAOLCA, 1 AAORCA $)$} \\
\hline \multicolumn{2}{|l|}{ Ostioplasty $=1(3 \%)$ AAORCA with CM } \\
\hline \multicolumn{2}{|l|}{ Patch ostioplasty $=2(5 \%)$ AAOLCA (1 CM) } \\
\hline \multicolumn{2}{|l|}{ Neo-ostial window creation with tacking $=1(3 \%)$ AAOLCA } \\
\hline \multicolumn{2}{|l|}{ Reimplantation $=1(3 \%)$ AAOLCA } \\
\hline \multicolumn{2}{|l|}{ Unroofing, aortocoronary window $=1(3 \%)$ AAOLCA } \\
\hline \multicolumn{2}{|l|}{ Unroofing, patch ostioplasty $=1(3 \%)$ AAORCA } \\
\hline \multicolumn{2}{|l|}{ Unroofing, reimplantation $=1(3 \%)$ AAORCA with $\mathrm{CM}$} \\
\hline Unroofing with tacking, patch ostioplasty, reimplantation $=1(3 \%)$ AAOLCA with CM & \\
\hline
\end{tabular}

\section{Anatomical Features Associated With Evidence of Ischemia and Sudden Cardiac Events}

This study showed, to our knowledge for the first time, that patients with ischemia were more likely to have AAOLCA versus AAORCA. No particular coronary artery was more likely in those with sudden cardiac events versus without sudden cardiac events. As well, twice the number of patients with sudden cardiac events had AAOLCA versus AAORCA, showing again that patients with AAOLCA are at higher risk for ischemia. However, in a comparison of the proportion of nonsudden cardiac event patients who had AAOLCA versus sudden cardiac event patients who had AAOLCA, no difference could be shown. Similarly, no difference could be found for AAORCA patients. Although the association of ischemia with AAOLCA has been suggested by previous studies, in this study we attempted to capture all patients with AAOCA, instead of specific subpopulations, to show these proportions and their significance. ${ }^{22,29}$ In addition, we showed that AAORCA is not always a benign lesion. In patients with ischemia, the proportion of AAOLCA to AAORCA was 1.4:1, and in those with sudden events, AAOLCA to AAORCA was 2:1.

We also identified several anatomic features that were associated with increased risk of ischemia: (1) an intramural

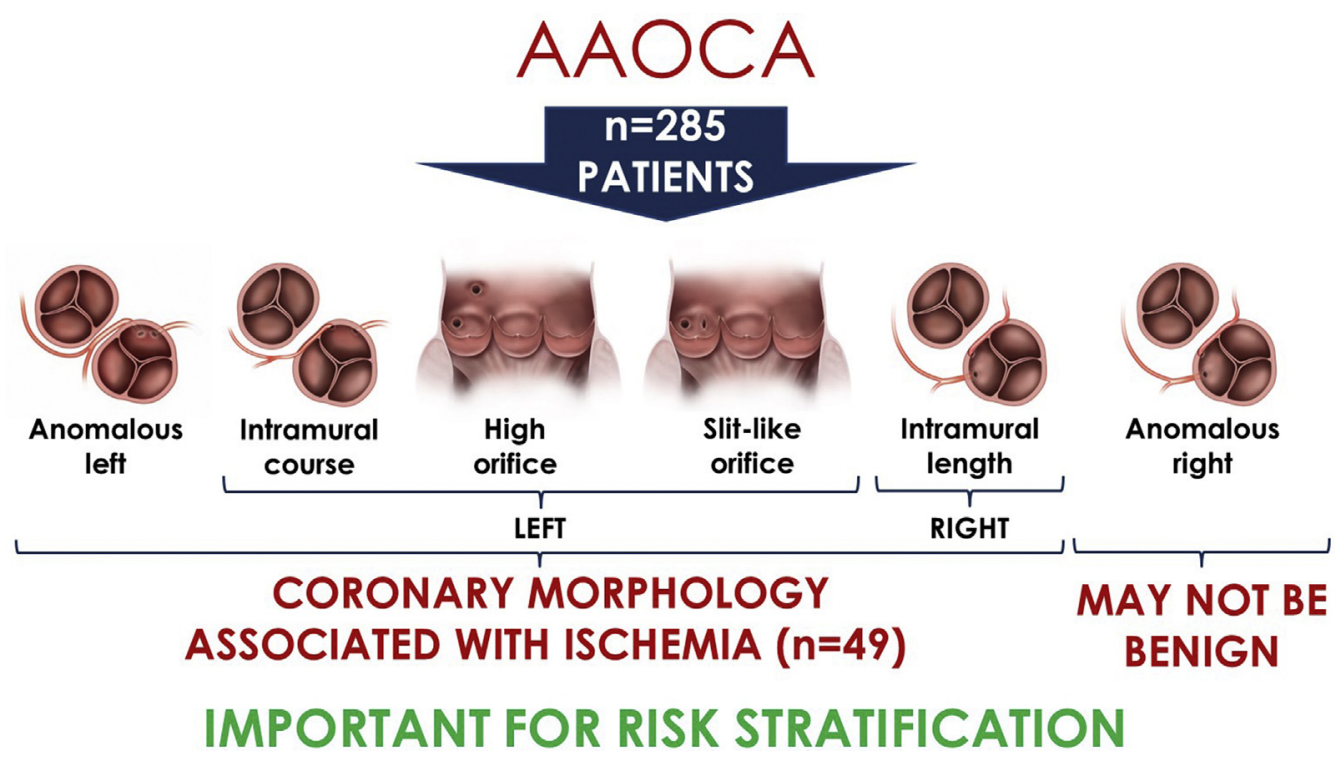

FIGURE 2. Primary findings related to myocardial ischemia in anomalous aortic origin of a coronary artery (AAOCA). 
course, a high take-off from the aorta, and/or a slit-like orifice in AAOLCA, and (2) a longer intramural course in AAORCA. Of the 18 patients who had a sudden cardiac event, all had AAOCA with a slit-like orifice and an interarterial coronary artery course, and all but 3 were intramural. We were perhaps unable to determine anatomic characteristics that were associated with patients who had sudden cardiac events because of their limited number in this study.

These results suggest that it is not the interarterial aspect per se, but the intramural course, increased intramural length, and a high and/or slit-like orifice that appear to contribute most to risk for ischemia. These details, which usually cannot be gleaned from echocardiographic imaging, are best determined using computed tomographic angiography or magnetic resonance imaging. ${ }^{4,30-32}$ Future studies should evaluate these characteristics in more detail. These features should be considered in risk assessments and potentially in future AAOCA expert guidelines, which currently recommend operation only for interarterial AAOLCA and for symptomatic patients. ${ }^{14,33}$

\section{Surgical Management}

Nearly all of the patients with ischemia who underwent operation had an unroofing procedure, similar to our previous report. ${ }^{18}$ Of these patients, $10 \%$ required reoperation to address ostial stenosis at various times. This finding, together with previous evidence for persistent ischemia after repair, suggests that techniques such as perioperative angiography (completion angiography) should be considered, and postoperative follow-up, including advanced imaging and perhaps provocative testing, are important.

\section{Limitations}

In addition to surgical patients, we enrolled nonsurgical and SCD patients in our cohort. We are primarily dependent on participating cardiologists at each site (not traditionally involved with the CHSS) to find these patients. As such, we do not know if we captured all patients at a given site, in addition to patients who never presented for care. It is also unknown whether patients treated at CHSS institutions are different, and potentially more complex, than those managed at nonparticipating sites. This might result in an inflation in the proportion of ischemic and surgical patients in our cohort. We also only included patients in our study who were diagnosed at less than or equal to 30 years. This age was selected to capture patients at highest risk of an ischemic event and because CHSS institutions generally treat pediatric and young adult patients; we would have missed a large proportion of older patients. ${ }^{15}$ Workup of patients was also variable, as evidenced by those without any provocative testing and the limited use of advanced techniques. As such, we did not include unclassified patients in our nonischemic group because we wanted the comparison group to be truly ischemia-negative, although we appreciate that this might introduce bias. Finally, our data accuracy is based on the accuracy of information sent from the participating member institutions. This is important because coronary artery anatomy was determined from institutional imaging reports rather than from expert review of images.

\section{Summary}

Within our large cohort of AAOCA patients, less than or equal to 30 years, we found that ischemia is more likely with AAOLCA, presence of an intramural course, a longer intramural course, and a high or slit-like orifice. However, no anatomic features distinguished those who presented with sudden cardiac events. We also established that AAORCA might not always be benign. AAORCA was present in just under half of patients with ischemia and one-third of those with sudden cardiac events. See Figure 2 for a graphical representation of these take-home messages. Notably, there was no statistically significant difference in the proportion of AAOLCA or AAORCA in patients with sudden cardiac events. Almost all ischemic patients underwent unroofing (most with tacking) as a primary procedure.

\section{CONCLUSIONS}

Our findings of associations between morphologic features and ischemia, and that AAORCA might not always be benign might provide a basis for improved risk stratification and refinements to standardized guidelines, including delineation of those at risk for ischemia and recommendations for surgery. Finally, there remains a strong need for the standardized workup of AAOCA patients and reporting of morphologic features, which will allow much needed easy aggregation and reporting of outcomes for these patients.

\section{Webcast}

You can watch a Webcast of this AATS meeting presentation by going to: https://aats.blob.core.windows. net/media/18May01/20ABC\%201.Plenary/S79_4.mp4.

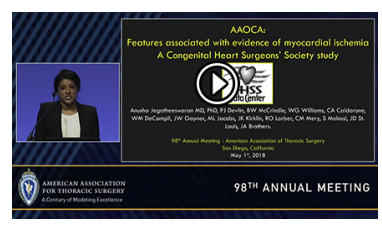

\section{Conflict of Interest Statement}

Authors have nothing to disclose with regard to commercial support.

The CHSS acknowledges the generous donations from Children's Mercy Hospitals and Clinics, the Michael H. Ludwig 
Memorial Foundation, and the Richard S. Wayne Endowed Chair of Pediatric Cardiology at the Children's Hospital of San Antonio.

\section{References}

1. Maron BJ, Haas TS, Ahluwalia A, Murphy CJ, Garberich RF. Demographics and epidemiology of sudden deaths in young competitive athletes: from the United States National Registry. Am J Med. 2016;129:1170-7.

2. Poynter JA, Williams WG, McIntyre S, Brothers JA, Jacobs ML, Congenital Heart Surgeons Society AAOCA Working Group. Anomalous aortic origin of a coronary artery: a report from the Congenital Heart Surgeons Society registry. World J Pediatr Congenit Heart Surg. 2014:5:22-30.

3. Brothers JA, McBride MG, Seliem MA, Marino BS, Tomlinson RS, Pampaloni MH, et al. Evaluation of myocardial ischemia after surgical repair of anomalous aortic origin of a coronary artery in a series of pediatric patients. J Am Coll Cardiol. 2007;50:2078-82.

4. Cheezum MK, Liberthson RR, Shah NR, Villines TC, O'Gara PT, Landzberg MJ, et al. Anomalous aortic origin of a coronary artery from the inappropriate sinus of Valsalva. J Am Coll Cardiol. 2017:69:1592-608.

5. Corrado D, Thiene G, Nava A, Rossi L, Pennelli N. Sudden death in young competitive athletes: clinicopathologic correlations in 22 cases. Am J Med. 1990;89:588-96.

6. Kragel AH, Roberts WC. Anomalous origin of either the right or left main coronary artery from the aorta with subsequent coursing between aorta and pulmonary trunk: analysis of 32 necropsy cases. Am J Cardiol. 1988;62:771-7.

7. Penalver JM, Mosca RS, Weitz D, Phoon CK. Anomalous aortic origin of coronary arteries from the opposite sinus: a critical appraisal of risk. $B M C$ Cardiovasc Disord. 2012;12:83

8. Taylor AJ, Byers JP, Cheitlin MD, Virmani R. Anomalous right or left coronary artery from the contralateral coronary sinus: "high-risk" abnormalities in the initial coronary artery course and heterogeneous clinical outcomes. Am Heart J. 1997;133:428-35.

9. Frescura C, Basso C, Thiene G, Corrado D, Pennelli T, Angelini A, et al. Anomalous origin of coronary arteries and risk of sudden death: a study based on an autopsy population of congenital heart disease. Hum Pathol. 1998;29:689-95.

10. Roberts WC, Siegel RJ, Zipes DP. Origin of the right coronary artery from the left sinus of Valsalva and its functional consequences: analysis of 10 necropsy patients. Am J Cardiol. 1982:49:863-8.

11. Maron BJ, Doerer JJ, Haas TS, Tierney DM, Mueller FO. Sudden deaths in young competitive athletes: analysis of 1866 deaths in the United States, 1980-2006. Circulation. 2009;119:1085-92.

12. Angelini P. Novel imaging of coronary artery anomalies to assess their prevalence, the causes of clinical symptoms, and the risk of sudden cardiac death. Circ Cardiovasc Imaging. 2014:7:747-54.

13. Mery CM, Lawrence SM, Krishnamurthy R, Sexson-Tejtel SK, Carberry KE, McKenzie ED, et al. Anomalous aortic origin of a coronary artery: toward a standardized approach. Semin Thorac Cardiovasc Surg. 2014;26:110-22.

14. Brothers JA, Frommelt MA, Jaquiss RDB, Myerburg RJ, Fraser CD Jr, Tweddell JS. Expert consensus guidelines: anomalous aortic origin of a coronary artery. J Thorac Cardiovasc Surg. 2017;153:1440-57.

15. Brothers JA, Gaynor JW, Jacobs JP, et al. The registry of anomalous aortic origin of the coronary artery of the Congenital Heart Surgeons' Society. Cardiol Young. 2010;20(Suppl 3):50-8

16. Brothers JA, Gaynor JW, Jacobs JP, Poynter JA, Jacobs ML. The Congenital Heart Surgeons' Society registry of anomalous aortic origin of a coronary artery: an update. Cardiol Young. 2015;25:1567-71.

17. Lorber R, Srivastava S, Wilder TJ, et al. Anomalous aortic origin of coronary arteries in the young: echocardiographic evaluation with surgical correlation. JACC Cardiovasc Imaging. 2015;8:1239-49.

18. Poynter JA, Bondarenko I, Austin EH, et al. Repair of anomalous aortic origin of a coronary artery in 113 patients: a Congenital Heart Surgeons' Society report. World J Pediatr Congenit Heart Surg. 2014:5:507-14.

19. Meza JM, Elias MD, Wilder TJ, Caldarone C, Jegatheeswaran A, Jacobs ML, et al. Exercise restriction is not associated with increasing body mass index over time in patients with anomalous aortic origin of the coronary arteries. Cardiol Young. 2017;27:1538-44.

20. Rautaharju PM, Surawicz B, Gettes LS, Bailey JJ, Childers R, Deal BJ, et al. AHA/ ACCF/HRS recommendations for the standardization and interpretation of the electrocardiogram: part IV: the ST segment, T and U waves, and the QT interval: a scientific statement from the American Heart Association Electrocardiography and Arrhythmias Committee, Council on Clinical Cardiology; the American

College of Cardiology Foundation; and the Heart Rhythm Society: endorsed by the International Society for Computerized Electrocardiology. Circulation. 2009; 119:e241-50.

21. Fletcher GF, Ades PA, Kligfield P, Arena R, Balady GJ, Bittner VA, et al. Exercise standards for testing and training: a scientific statement from the American Heart Association. Circulation. 2013;128:873-934.

22. Basso C, Maron BJ, Corrado D, Thiene G. Clinical profile of congenital coronary artery anomalies with origin from the wrong aortic sinus leading to sudden death in young competitive athletes. J Am Coll Cardiol. 2000;35: 1493-501.

23. Cheitlin MD, De Castro CM, McAllister HA. Sudden death as a complication of anomalous left coronary origin from the anterior sinus of Valsalva, a not-so-minor congenital anomaly. Circulation. 1974:50:780-7.

24. Eckart RE, Scoville SL, Campbell CL, Shry EA, Stajduhar KC, Potter RN, et al. Sudden death in young adults: a 25 -year review of autopsies in military recruits. Ann Intern Med. 2004;141:829-34.

25. Maron BJ, Haas TS, Ahluwalia A, Rutten-Ramos SC. Incidence of cardiovascular sudden deaths in Minnesota high school athletes. Heart Rhythm. 2013;10: 374-7.

26. Maron BJ, Haas TS, Murphy CJ, Ahluwalia A, Rutten-Ramos S. Incidence and causes of sudden death in U.S. college athletes. J Am Coll Cardiol. 2014;63: $1636-43$.

27. Pilmer CM, Kirsh JA, Hildebrandt D, Krahn AD, Gow RM. Sudden cardiac death in children and adolescents between 1 and 19 years of age. Heart Rhythm. 2014; 11:239-45.

28. Krasuski RA, Magyar D, Hart S, Kalahasti V, Lorber R, Hobbs R, et al. Longterm outcome and impact of surgery on adults with coronary arteries originating from the opposite coronary cusp. Circulation. 2011;123:154-62.

29. Taylor AJ, Rogan KM, Virmani R. Sudden cardiac death associated with isolated congenital coronary artery anomalies. J Am Coll Cardiol. 1992;20:640-7.

30. Cheezum MK, Ghoshhajra B, Bittencourt MS, Hulten EA, Bhatt A, Mousavi N, et al. Anomalous origin of the coronary artery arising from the opposite sinus: prevalence and outcomes in patients undergoing coronary CTA. Eur Heart J Cardiovasc Imaging. 2017;18:224-35.

31. Ashrafpoor G, Danchin N, Houyel L, Ramadan R, Belli E, Paul JF. Anatomical criteria of malignancy by computed tomography angiography in patients with anomalous coronary arteries with an interarterial course. Eur Radiol. 2015;25: 760-6.

32. Harris MA, Whitehead KK, Shin DC, Keller MS, Weinberg PM, Fogel MA. Identifying abnormal ostial morphology in anomalous aortic origin of a coronary artery. Ann Thorac Surg. 2015;100:174-9.

33. Van Hare GF, Ackerman MJ, Evangelista JA, Kovacs RJ, Myerburg RJ, Shafer KM, et al. Eligibility and disqualification recommendations for competitive athletes with cardiovascular abnormalities: Task Force 4: congenital heart disease: a scientific statement from the American Heart Association and American College of Cardiology. Circulation. 2015;132:e281-91.

Key Words: anomalous aortic origin of a coronary artery, congenital heart disease, database, epidemiology, ischemia

\section{Discussion}

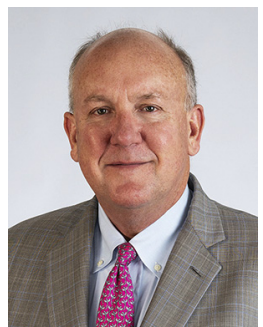

Dr Charles D. Fraser (Houston, Tex). I would really like to thank the Association for the privilege of discussing this important presentation. Dr Jegatheeswaran has done her usual masterful job of presenting important information for us to consider in this vexing topic of anomalous aortic origin of the coronary artery, or AAOCA. I have also had the advantage of reading the manuscript, and I know that time limited some of the data that Dr Jegatheeswaran could present, so I will embellish a little bit on that. 
She and colleagues have analyzed data from the Congenital Heart Surgeons Society AAOCA registry, which is a critically important prospective registry now of over 560 patients. To re-emphasize, AAOCA may or may not be associated with demonstrable myocardial ischemia or sudden cardiac death. The majority of patients are actually incidentally discovered to have this lesion, and that's recently more frequently associated with mass screening programs, which are controversial.

Even in the absence of ischemia or symptoms, the diagnosis is problematic: it's confusing for practitioners; it's frightening for patients and families who may be essentially disabled by the diagnosis; there's uncertainty regarding surgery and approach, activity limitations, and long-term surveillance.

Recent guidelines, which I participated in creating, have recommended surgery for patients with an interarterial anomalous left coronary artery or patients with either anomalous left or right coronary arteries and evidence of ischemia. Dr Jegatheeswaran's data bring many new important revelations. Among these, the proportion of African Americans with ischemia was significantly higher than other races. Anomalous right coronary artery is less likely to have ischemia but it's not totally benign. Despite the guidelines, a very large percentage of patients with anomalous right coronary arteries do undergo surgery. A longer documented intramural course increases the risk of ischemia. Almost $50 \%$ of patients without provocative evidence of ischemia do actually undergo surgery.

Very concerning, among the 40 patients with ischemia who underwent surgery, $10 \%$ required an ostial revision or had a problematic operation. And then finally, the specific anatomic features associated with ischemia include an intramural course, a high take-off, a slit-like ostium for anomalous left, and a longer intramural course of anomalous right.

So I have many questions I could ask. I will start with, given the findings of the specific anatomic features associated with increased risk, particularly the length of intramurality, what is your recommended diagnostic assessment methodology?

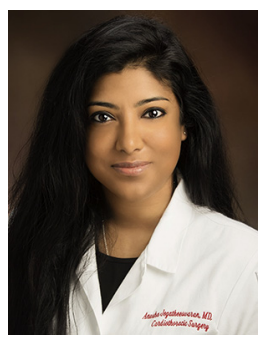

Dr Anusha Jegatheeswaran (Toronto, Ontario, Canada). Thanks for your question, Dr Fraser. Many people want to know what method should be used, and I think that's a complex question, because different centers have had good results using different methodologies. I think it is important that we acknowledge those results and that I also mention this study was not designed to answer that question.

In addition, people often want to know, what the length of the intramural segment is. There has not been great correlation between advanced imaging and intraoperative findings as we know. We are yet to figure out which modality is able to capture this best. The first step to figure this out is standardized reporting. I will make a plea to all of you to help us get that data by following a standard approach. Despite the fact that intraoperatively at Texas Children's Hospital, a unique technique is used to measure the length of the intramural segment by using a suture, that's not the data that clinicians have preoperatively to make their decisions. So, although it's great to get that exact measurement, that's never what a physician has when they are making their clinical assessment. We have yet to figure out which method will allow us to best figure it out preoperatively, even if it means using whatever technique is done best at your institution. However, hopefully we will move toward a standard way of figuring that out and all centers will be able to adopt that technique for use preoperatively, intraoperatively, and also postoperatively.

Dr Fraser. Completely agree.

Given these findings, which are, again, very important, should the guidelines be revisited and in some way revised, and if so, how?

Dr Jegatheeswaran. Currently the guidelines are really just expert consensus documents. However, it includes some of the best data that we have right now. Similarly, what we just presented could be included among these data. We had 550 patients with detailed abstraction of their reports. These data were not core lab-reviewed. One of our next steps is to review every preoperative image in the core lab, and then further determine which morphologic variants are associated with increased risk.

The current consensus guidelines were primarily developed from military autopsy series and the data of competitive athletes who died suddenly. Our data do have something important to add to that, but it is by no means the final answer.

Dr Fraser. Okay, thank you. I have to ask, what are your thoughts on mass screening programs? Is this an advisable thing, going into large school districts, screening all high school age students?

Dr Jegatheeswaran. So that's a really contentious issue, as we all know-

Dr Fraser. That's why I asked.

Dr Jegatheeswaran. - and I don't think we have the right answer. It's a paradox. Likely we will screen everybody, find some patients who have benign lesions and then inadvertently operate on them, despite the surgical risks. However, we truly don't have the answers as to what to do with those patients yet. Even performing ECGs in athletes is contentious, and although Europe has adopted that, the United States has yet to do so. Mass screening is an order of magnitude more invasive.

I think the problem is that what we really need is the longterm follow-up of this large multi-institutional cohort. 
There are so many variations... in fact, there are an exponential number of variations, and we haven't yet figured out what to do with each variant. So, we need long-term follow-up, and of course we must consider the cost versus benefit of screening. I think when we know something more definitive, such as how to risk-stratify patients, we can consider moving toward mass screening to identify morphologic variants or likely high-risk combination of features that are currently unknown. However, we are not there yet.

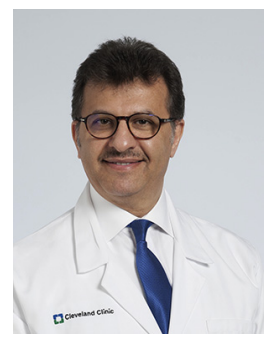

Dr Hani Najm (Cleveland, Ohio). I want to congratulate you on this important study and collection of a very large number of those patients, which, I agree with you, we have a lot of unanswered questions.

You have indicated in your presentation the number of patients who have had ischemia in the left and right anomalies as well as patients who had cardiac events in the left and right anomalies. Have you correlated those patients who had cardiac events with those patients who have had cardiac ischemia? Because what we found was that not infrequently, and I am sure surgeons around the room would agree, you establish ischemia before surgery, you do the surgery and you still have some ischemia postop. And it depends on what kind of ischemia study you have done and how elaborate that is; there is always a false positive and/or a false negative in all these studies. So I agree that there are still a lot of unanswered questions. We started doing PET scans to look at ischemia and FFRs, utilizing our adult colleagues experience, to tell us whether these are significant or not.

So going forward, first of all, if you could address the correlation between the presence or absence of ischemia and the cardiac events, and do our surgeries fix the ischemia, and what is the best modality of detecting ischemia? Is it the FFR, is it functional or anatomical measures that would be best for those patients?

Dr Jegatheeswaran. With regard to correlation, the sudden cardiac event patients in our study were a subset of the ischemia patients. There were 49 ischemia patients, 18 of whom had sudden cardiac events. We couldn't find any anatomic features associated with patients who had sudden cardiac events. Part of that is probably because we only had 18 patients, so it was a really small subgroup in which to look for features. What we need is a larger cohort of patients, and we are still enrolling in order to figure out that answer.

In terms of postoperative ischemia versus preoperative ischemia, we don't have that data in our study, so we are unable to answer that. We are still doing follow-up on these patients, and for a lot of the patients we don't yet have their postoperative evaluations.
And with regard to your last question, I don't know what the answer is with respect to the best method. We know for provocative testing sometimes it's positive, sometimes it's negative, and different circumstances may cause you to have ischemia in some instances versus others. So currently, we don't have a gold standard method. Of course, it would be nice to do something that is not invasive, as opposed to FFR.

Dr Fraser. So I have to end with one hard question. You are now the world's expert on this subject. All the patients that have been enrolled in the study consented. I know from our experience that they are expecting some follow-up. So I will bet that what's going to happen is you are going to get called by a family, and the question is going to go like this:

I have a 14-year-old daughter who is a soccer player and I'm really worried that she might have a problem. She is asymptomatic. She has gotten an echo and she has got an anomalous right coronary artery from the left sinus, it goes right behind the pillar, and it looks to have about a 6- to 7$\mathrm{mm}$ intramural segment. Asymptomatic, provocative testing is negative.

Dr Jegatheeswaran. That's a great question and this is the conundrum that we face, which is why we are doing this study and why you are asking me this question. This study really wasn't designed for individual patient prediction. Right now we don't have the answer, partially because we don't have long-term follow-up.

Of course, what we did find in our study is that there is a risk for surgery. We had 4 patients who had reoperations for ostial stenosis. So, we don't want to give patients the false hope that surgery is going to solve everything. Of course, it's a small number; we need more patients and long-term follow-up to get a clearer picture of the risks.

Because patients have numerous subtleties and combinations of features, in order to accrue any kind of meaningful data we need more patients, more data, and then one day hopefully we will be able to develop a calculator for prediction of who should undergo what type of surgery or management on the basis of their anatomical features. That's really our ultimate goal.

Dr Fraser. I think your data suggest most of those patients are getting an operation.

Dr Jegatheeswaran. The data definitely do suggest that. We had 236 patients who had negative ischemia testing. Of course, we know negative ischemia testing doesn't actually mean they are negative, but $46 \%$ of those patients despite negative ischemia testing underwent surgery.

In many cases, I'm sure that the surgeons are forced to operate. However, the caveat is that we don't know what the right answer is yet.

Dr Fraser. Very well done. Thank you. 


\section{APPENDIX E1. MEMBER INSTITUTIONS}

Johns Hopkins All Children's Hospital, Tampa, Florida Arnold Palmer Hospital for Children, Orlando, Florida Cleveland Clinic Foundation, Cleveland, Ohio

Cardinal Glennon Children's Hospital, St. Louis, Missouri

Boston Children's Hospital, Boston, Massachusetts

Ann \& Robert H. Lurie Children's Hospital, Chicago, Illinois

Children's Hospital of Michigan, Detroit, Michigan

Children's Minnesota, Minnesota, Minneapolis

Cincinnati Children's Hospital Medical Center, Cincinnati, Ohio

Children's Hospital of Philadelphia, Philadelphia, Pennsylvania

Children's Hospital of Pittsburgh, Pittsburgh,

Pennsylvania

Rudy Children's Hospital, San Diego, California

Seattle Children's Hospital, Seattle, Washington

Children's Hospital of Wisconsin, Milwaukee, Wisconsin

Children's Mercy, Kansas City, Missouri

Children's National, Washington, District of Columbia

Cedars-Sinai Medical Center, Los Angeles, California

Nemours/Alfred I. Dupont Hospital for Children, Wilmington, Delaware

Children's Healthcare of Atlanta, Atlanta, Georgia

Inova Children's Hospital. Fall's Church, Virginia

The Hospital for Sick Children, Toronto, Ontario

Johns Hopkins Children's Center, Baltimore, Maryland

Levine Children's Hospital, Charlotte, North Carolina

Loma Linda University Children's Hospital, Loma Linda, California

Nicklaus Children's Hospital, Miami, Florida

C.S. Mott Children's Hospital, Ann Arbor, Michigan

Mayo Clinic Children's Center, Rochester, Minnesota

Children's Hospital at Montefiore, Bronx, New York

Kravis Children's Hospital at Mount Sinai, New York, New York

MUSC Children's Hospital, Charleston, South Carolina

Hassenfeld Children's Hospital, New York, New York

Primary Children's Hospital, Salt Lake City, Utah

St. Louis Children's Hospital, St. Louis, Missouri

Lucile Packard Children's Hospital, Palo Alto, California

Texas Children's Hospital, Houston, Texas

Tulane Hospital for Children, New Orleans, Louisiana

Stollery Children's Hospital, Edmonton, Alberta

University of Texas Southwestern Medical Center, Dallas, Texas

Masonic Children's Hospital, Minnesota, Minneapolis

Yale New Haven Children's Hospital, New Haven, Connecticut

\section{APPENDIX E2. INCLUSION AND EXCLUSION CRITERIA, DATA COLLECTION, DATA AGGREGATION OF ANATOMICAL FEATURES, AND DETAILED STATISTICAL METHODS Inclusion and Exclusion Criteria}

Inclusion criteria for the registry are a diagnosis of AAOCA at less than or equal to 30 years, with a structurally normal heart or a hemodynamically insignificant concomitant cardiac lesion (eg, patent ductus arteriosus, atrial septal defect, restrictive ventricular septal defect, mild pulmonary valve stenosis, or bicuspid aortic valve without stenosis) not requiring surgical or catheter-based intervention. Exclusion criteria are coronary artery ostial atresia, coronary artery aneurysm, myocardial bridging, coronary-cameral fistula, anomalous aortic origin of a coronary artery from the pulmonary artery, and any concomitant hemodynamically significant structural heart lesion.

\section{Data Collection}

Patient data were abstracted from copies of institutional medical records submitted to the CHSS Data Center, for initial and subsequent assessments, hospitalizations, and procedures, and entered into a database by CHSS Data Center staff. These variables have been defined and described in our previous work and include patient demographic characteristics, presentation, and symptoms from clinic notes, operative details from reports, and anatomical details from imaging reports, operative records, and autopsy reports. ${ }^{2}$ Coronary artery anatomy was depicted as individual morphologic components for classification and analysis as shown in the standardized atomization form given to participating centers, as previously described (Online Data Supplement). Anatomical components collected included which coronary artery is anomalous, the morphology of the origin ( 2 orifices, common orifice, single orifice with common trunk, slit-like orifice, high take-off, acute angulation), and the course of the coronary artery.

The anatomical features collected for each patient were based on data obtained from preoperative echocardiogram, computed tomography, and/or magnetic resonance imaging reports. In addition, surgical atomization reports completed by the surgeon were used, if the patient underwent an operation. If these were not provided, a report was completed by Data Center staff using the operative report. In several cases, the only anatomic description available was from an autopsy report $(\mathrm{n}=4)$. We have also previously described our method for using multiple patient reports to obtain missing data or clarify contradictory data for the same patient.

\section{Data Aggregation of Anatomical Features}

Aggregated composite morphology for each patient was based on available diagnostic studies, and surgical data. 
Similar to the technique used in our previous report, only preoperative diagnostic studies were used, before any surgical procedures. These were concatenated to reflect the global morphology of each patient using an algorithm that first retained all values that were similar among all sources (echocardiograms, computed tomography, magnetic resonance imaging, operative notes, and surgeon-completed data forms), then the variables that were only available from one source were added. Finally, if a variable had differing values, these were adjudicated by Data Center staff. The gold standard was considered to be a data form that was completed by the surgeon on the basis of his/her intraoperative findings, followed by operative notes, magnetic resonance imaging or computed tomography, and finally echocardiography.

\section{Statistical Methods}

Categorical variables were summarized using frequencies and percentages. The normality of all continuous variables was first evaluated with the Shapiro-Wilk test. Continuous variables were then summarized as medians and interquartile ranges (if non-normal) or, if normally distributed, means and standard deviations. The $\chi^{2}$ and Fisher exact tests were used to evaluate differences between groups for categorical variables, whereas the Wilcoxon signed rank test was used to evaluate differences between groups for non-normal continuous variables, and the Student $t$ test for normal continuous variables.

\section{APPENDIX E3. DETAILED DESCRIPTION OF 9 PATIENTS WITH ISCHEMIA WHO DID NOT UNDERGO SURGERY.}

Nine patients with ischemia did not undergo an operation; 5 had anomalous aortic origin of a left coronary artery (AAOLCA); 1 sudden cardiac death, 1 with sudden cardiac arrest (SCA) died, 1 had SCA while being admitted after presentation with symptoms/elevated biomarkers/abnormal electrocardiogram and died, 2 declined an operation, and 4 had anomalous aortic origin of a right coronary artery (1 with SCA died, 1 lacked follow-up, 2 were referred for an operation). The 2 AAOLCA patients who were alive and had not had an operation both presented with abnormal perfusion scans. One was reluctant to undergo an operation and wanted a second opinion (interarterial AAOLCA with an intramyocardial left anterior descending artery), and the other patient refused to undergo an operation (interarterial intramural AAOLCA with a high ostial take-off at the level of the sinotubular junction). 
TABLE E1. Comparison of patients without ischemia versus unclassified patients

\begin{tabular}{|c|c|c|c|c|c|c|c|c|c|}
\hline \multirow{2}{*}{$\begin{array}{c}\text { Anomalous coronary } \\
\text { artery }\end{array}$} & \multirow{2}{*}{$\frac{\text { Total }}{\text { N }(\%)}$} & \multirow{2}{*}{$\frac{\text { Dead }}{\text { n }(\%)}$} & \multirow{2}{*}{$\frac{\text { Surgery }}{\text { n }(\%)}$} & \multirow{2}{*}{$\frac{\text { Interarterial }}{n(\%)}$} & \multirow{2}{*}{$\frac{\text { Intramural }}{\mathrm{n}(\%)}$} & \multicolumn{2}{|l|}{$\begin{array}{l}\text { Intramural } \\
\text { length, mm }\end{array}$} & \multirow{2}{*}{$\begin{array}{c}\begin{array}{c}\text { High } \\
\text { orifice }\end{array} \\
\text { n (\%) }\end{array}$} & \multirow{2}{*}{$\begin{array}{c}\begin{array}{c}\text { Slit-like } \\
\text { orifice }\end{array} \\
\text { n }(\%)\end{array}$} \\
\hline & & & & & & $\overline{\text { Median (IQR) }}$ & $\overline{\mathbf{M}}$ & & \\
\hline \multicolumn{10}{|c|}{ Patients without ischemia $(\mathrm{n}=236)$} \\
\hline AAOLCA & 46/236 (19) & $1 / 46(2)$ & $23 / 46(50)$ & $34 / 41(83)$ & $18 / 35(51)$ & $7.5(4.5-10)$ & 5 & $2 / 32(6)$ & $10 / 28(36)$ \\
\hline AAORCA & $184 / 236(78)$ & $1 / 184(1)$ & $85 / 184(46)$ & $158 / 161(98)$ & $114 / 131(87)$ & $6(4.8-9)$ & 38 & $44 / 105(42)$ & $62 / 81(77)$ \\
\hline LAD & $3 / 236(1)$ & 0 & 0 & 0 & 0 & 0 & 0 & 0 & 0 \\
\hline Circumflex & $2 / 236(1)$ & 0 & 0 & $1 / 2(50)$ & 0 & 0 & 0 & 0 & 0 \\
\hline $\begin{array}{l}\text { Both (AAOLCA } \\
\text { and AAORCA) }\end{array}$ & $1 / 236(0.4)$ & 0 & $(1 / 1) 100$ & 0 & $1 / 1(100)$ & 1.5 & 0 & $1 / 1(100)$ & $1 / 1(100)$ \\
\hline Total & $236 / 236(100)$ & $2 / 236(1)$ & $109 / 236(46)$ & $193 / 208(93)$ & $133 / 170(78)$ & $6(4.5-9)$ & 43 & $47 / 140(34)$ & $73 / 111(66)$ \\
\hline \multicolumn{10}{|c|}{ Unclassified patients $(\mathrm{n}=275)$} \\
\hline AAOLCA & $54 / 275(20)$ & $2 / 54(4)$ & $38 / 54(70)$ & $39 / 43(91)$ & $34 / 42(81)$ & $5.8(5-9)$ & 12 & $10 / 31(32)$ & $24 / 36(67)$ \\
\hline AAORCA & $213 / 275$ (77) & $4 / 213(2)$ & $127 / 210(60)$ & $180 / 182(99)$ & $125 / 149(84)$ & $7(5-10)$ & 33 & $38 / 131(29)$ & $77 / 110(70)$ \\
\hline LAD & $2 / 275(1)$ & 0 & 0 & $1 / 2(50)$ & $0,2 \mathrm{M}$ & - & 0 & $0,2 \mathrm{M}$ & $0,2 \mathrm{M}$ \\
\hline $\begin{array}{l}\text { Both (AAOLCA } \\
\text { and AAORCA) }\end{array}$ & $6 / 275(2)$ & 0 & $3 / 6(50)$ & $6 / 6(100)$ & $2 / 6(33)$ & $2.3(1-3.5)$ & 0 & $5 / 6(83)$ & 0/4 (100) \\
\hline Total & $275 / 275(100)$ & $6 / 275(2)$ & $168 / 272(62)$ & $226 / 233$ (97) & $161 / 197(82)$ & $7(5-10)$ & 45 & $53 / 168(32)$ & $101 / 150(67)$ \\
\hline \multicolumn{10}{|c|}{$P$ values for patients without ischemia vs unclassified patients } \\
\hline AAOLCA & 1.0 & 1.0 & .04 & .3 & .006 & .5 & & .01 & .01 \\
\hline AAORCA & .9 & .4 & .005 & .7 & .5 & .3 & & .04 & .3 \\
\hline Total & - & .3 & .0004 & .04 & .4 & 6 & & .7 & .8 \\
\hline
\end{tabular}

There were 6 patients who died within the unclassified patient group, of whom 2 AAOLCA patients died in the immediate postoperative period, and 4 died from noncardiac causes. We found that 5 centers contributed 10 to 25 patients each to the patients who underwent surgery among the unclassified patients, suggesting these centers had a strategy of operating on anomalous aortic origin of a coronary artery without provocative testing. This is compared with 3 entirely different centers, which contributed 10 to 18 patients each to the patients who underwent surgery among the patients without ischemia. This again suggests an alternate strategy of provocative testing before surgery. Missing values not shown can be derived by comparing the denominator with the number of patients in the Total column. High orifice denotes those at or above the sinotubular junction. In the Surgery column, patients who died and were not eligible for surgery were removed from the denominator. IQR, Interquartile range; $M$, missing; $A A O L C A$, anomalous aortic origin of a left coronary artery; $A A O R C A$, anomalous aortic origin of a right coronary artery; $L A D$, left anterior descending. 